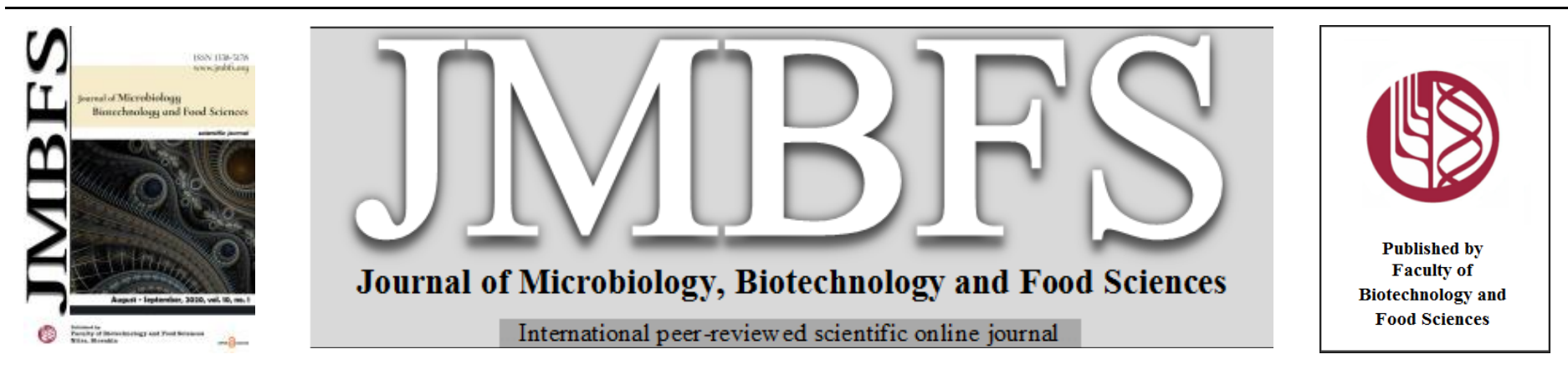

\title{
INTERACTION OF SELECTED LACTIC ACID BACTERIA AND YEAST IMPROVES THE QUALITY OF PEARL MILLET SOURDOUGH BREAD
}

\author{
Stephen Abiola Akinola* ${ }^{1,2}$, Collins Njie Ateba ${ }^{2}$, Mulunda Mwanza ${ }^{3}$, Oluwatooyin Faramade Osundahunsi ${ }^{1}$ \\ Address(es): Mr Stephen Abiola AKINOLA, \\ ${ }^{1}$ Department of Food Science and Technology, Federal University of Technology Akure, P.M.B. 704, Akure, Nigeria, +234(0) 706 7803570. \\ ${ }^{2}$ Department of Microbiology, North-West University Mafikeng, Private Bag X2046 Mmabatho 2745, Mmabatho, North-West Province, South Africa. \\ ${ }^{3}$ Center for Animal Health Studies, Faculty of Natural and Agricultural Sciences, North-West University, Private Bag X2046 Mmabatho, 2745 , South Africa.
}

*Corresponding author: akinolastephen3@gmail.com

doi: 10.15414/jmbfs.2020.10.1.22-27

ARTICLE INFO

Received 9.3. 2019

Revised 19. 2. 2020

Accepted 3. 3. 2020

Published 1. 8. 2020

Regular article

open $\partial_{\text {ACCESS }}$

\section{ABSTRACT}

The effect of lactic acid bacteria and yeast interaction on the quality of pearl millet (PM) sourdough bread was investigated. Lactobacillus plantarum (A), Pediococcus pentosaceus (B), Lactobacillus pentosus (C), Saccharomyces cerevisiae (D) and Candida milleri (E) cultures were used singly and in combinations in sourdough fermentation. The proximate, physical and sensory properties of bread were evaluated using standard methods. The protein content ranged from 13.07\% - 14.32\%, ash $(1.77 \%-1.99 \%)$, fat $(8.01 \%$ $9.32 \%)$, crude fibre $(0.77 \%-1.25 \%)$, moisture $(21.08 \%-22.65 \%)$, carbohydrate $(51.28 \%-54.23 \%)$, loaf weight $(75.28 \mathrm{~g}-108.32 \mathrm{~g})$, loaf volume $(89 \mathrm{~cm} 3-130 \mathrm{~cm} 3)$ and specific volume $(1.0 \mathrm{~cm} 3 / \mathrm{g}-1.26 \mathrm{~cm} 3 / \mathrm{g})$. PMABE (Pearl Millet + Lb. plantarum + Lb. pentosus + C. milleri) was scored acceptable. The crude protein, fat, ash, fibre content and specific volume differed depending on the type of starters used in the development of sourdough bread. The use of co-cultures as starters could improves the physicochemical quality and acceptability of sourdough bread. Saccharomyces cerevisiae have been implicated in dough development, however, this study have shown that Candida milleri could also be a substitute in dough development in the pastry industry.

Keywords: Pearl millet, Quality characteristics, Sourdough, bread, Starter Culture, LAB, Yeast

\section{INTRODUCTION}

Millets are major sources of energy and protein in Sub-Saharan Africa (SSA) with dominant species been pearl millet (Ogunbanwo and Ogunsanya, 2012). Pearl millet (Pennisetum glaucum) is one of the major cereal typical of tropical and subtropical regions of the world and constitutes a staple diet for human consumption but still underutilised (Balasubramanian and Viswanathan, 2010). Fermentation is an age long techniques often done under spontaneous conditions. Spontaneous fermentation is plagued with safety issues as pathogens seldomly find their way into fermentation substrate due to the use of non-defined cultures. Hence, the need to optimize fermentation process for desirable product quality. Starter cultures are preparations containing large numbers of variable microorganisms (Kołożyn-Krajewska and Dolatowski, 2012) which may be added to accelerate a fermentation process. Starter cultures are natural isolates of desirable microorganisms found normally in substrates (De Vuyst and Vancanneyt, 2007).

Sourdough is an acidic paste used to improve quality of breads (Thiele $\boldsymbol{e t}$ al., 2002), biscuits and cakes (Ottogalli et al., 1996) often prepared through spontaneous or control fermentation of moistened cereal flours. Microbial diversity of sourdough is usually variable, having a predominance of lactic acid bacteria and yeasts (Akinola and Osundahunsi, 2017). Yeast pre-ferment have been used and are still applied for dough development towards white bread production. Sourdough contains lactic acid bacteria that produces mainly organic acids and yeasts that produce carbon dioxide and ethanol as byproducts of metabolism. Interactions between yeasts and lactobacilli are important for the metabolic activity of sourdoughs (Kaisa et al., 2009). Indeed, most traditional fermentations results from the combined metabolic activities of different types of microorganisms.

Sourdough contains both homo and heterofermentative lactic acid bacteria in coexistence with yeasts which have great potential to impart desirable characteristics on a final product. The use of sourdough in baking gluten-free bread has been described effective in the improvement of product texture and the delay of staling of the gluten-free breads (Moore $\boldsymbol{e t}$ al., 2008). The improved textural properties reported in sorghum sourdough bread has been linked to the metabolic activities of exopolysaccharide (EPS) producing strains Leuconostoc mesenteriodes (Schober et al., 2007; Schwab et al., 2008). Hounhouigan et al.
(1999) reported a stimulating effect of Candida krusei on $L$. fermentum and $L$. brevis used as a mixed starter culture in the production of fermented maize product - mawe. Edema and Sanni (2008) reported the importance of the interaction between lactobacilli and yeast in the modulations of microflora and dynamics of sour maize meal which is critical to the development of sourdough bread. However, little or none have been reported on the effect of selected starters on quality characteristics of millet sourdough fermentation. Bread have been produced from spontaneously developed sourdough but with occurrence of several potential pathogens of both bacteria and fungi origin. Hence, the concern for starter specificity to ensure safety and improved yield.

The use of less known cereals in sourdough development in the confectionary industry is only in its infancy in Sub-Saharan Africa (Arendt et al., 2007), yet there are many substrates laden with potentials for use in sourdough products. Millet is one of such promising substrates, particularly as it's a rich source of carbohydrate and considerable amount of protein relative to other cereals apart from wheat. Millet lacks gluten which is a major source of concern in coeliac diseases patients (Padalino et al., 2016). Production of bread and other pastry products from gluten-free cereals such as millet is a challenge to processors since, it lacks the structure that provides the visco-elastic properties in doughs (gluten). Therefore, sourdough technology is of choice in improving the technological properties of millet doughs. Type of substrate, temperature, titratable acidity, $\mathrm{pH}$ of dough and starter cultures used in fermentation are among the factors that affects the quality of sourdough (Chavan and Chavan, 2011). Hence, this study investigated the effect of selected lactic acid bacteria and yeast (starters) on quality characteristics of sourdough bread produced from pearl millet flour.

\section{MATERIAL AND METHODS}

\section{Materials}

Pearl millet (Pennisetum glaucum) grains were obtained from Terminus market, Jos, Plateau state, Nigeria and was processed into flour as described by Akinola et al., (2017). Pearl millet flour was stored in airtight polyethene bag prior to further analysis. Lactobacilli (Lactobacillus plantarum, Pediococcus pentosaceus and Lactobacillus pentosus) and yeast (Saccharomyces cerevisiae and Candida 
milleri) used in the study were typed isolates from spontaneously developed millet sourdough (Akinola and Osundahunsi, 2017). These cultures were kept until use under frozen storage at the Food Microbiology Laboratory, Department of Food Science and Technology, Federal University of Technology, Akure, Nigeria. All chemical used in this study were of analytical grade purchased from Merck, South Africa.

\section{Methods}

\section{Development of millet sourdough}

Previously typed cultures of lactic acid bacteria (Lactobacillus plantarum, Pediococcus pentosaceus and Lactobacillus pentosus) and yeast (Saccharomyces cerevisiae and Candida milleri) from spontaneously developed pearl millet sourdough was used in the study. Cultures were inoculated both singly and in combinations into the pearl millet slurry for sourdough development. Cultures were re-activated overnight in appropriate media broths. Lactic acid bacteria and yeast cultures were sub-cultured on de mann Rogosa Sharpe agar (MRS Agar, Oxoid, UK) and malt extract agar (Oxoid, UK) at $30^{\circ} \mathrm{C}$ for $48 \mathrm{~h}$ and $26^{\circ} \mathrm{C}$ for 72 $\mathrm{h}$ incubation time respectively. Pure colonies were grown in nutrient broth an were centrifuged (Stuartt microfuge SRFC 2) at $8000 \mathrm{x}$ g for $10 \mathrm{~min}$, washed in $1 \%$ phosphate buffer ( $\mathrm{pH} 7.0$ ), sterile distilled water and re-centrifuged. The density of the harvested inoculum was adjusted to $1.0 \mathrm{McFarland}$ concentration $\left(1.0 \times 10^{7}\right.$ cells $\left./ \mathrm{ml}\right)$ using a calibrated densitometer (Densimat, BioMerieux, Marcy-1'Etoile, France). Thereafter, to about $50 \mathrm{~g}$ of flour, $5 \mathrm{ml}$ of cell culture was added as inoculum singly and in multiple combination to achieve a $1.0 \times 10$ $\mathrm{CFU} / \mathrm{ml}$ concentration. The resulting mixture was made up with sterilised water to $50 \mathrm{ml}$ mark in a screw cap glass bottles (w/v: 1:1). Mixing was done to obtain a soupy consistency at ambient temperature $\left(29 \pm 2{ }^{\circ} \mathrm{C}\right)$ using a glass rod. Mixture was fermented till a pH $\leq 4.5$ was attained in all batter (Edema, 2011) while the control sample (sourdough without starter culture) was fermented spontaneously.

\section{Production of sourdough bread}

The modified batter method described by Edema (2013) was used in the production of sourdough bread as shown in Figure 1. The total percent of flour needed to produce a sourdough bread was used to calculate the weight of other ingredients. To about $126 \mathrm{~g}$ pearl millet flour, $30 \%$ of sourdough was mixed in a clean glass bowl alongside baking fat $(18 \mathrm{~g})$, salt $(0.9 \mathrm{~g})$, granulated sugar $(45 \mathrm{~g})$ and $(1.87 \mathrm{~g})$ flour improver. The method used involved two mixing stages in which all ingredients including sourdough batters were mixed for $10 \mathrm{~min}$ at high speed (Philips hand mixer Type HR 1453). The developed batter was allowed to stand for $4 \mathrm{~h}$ at room temperature $\left(28 \pm 2{ }^{\circ} \mathrm{C}\right)$ for leavening. The batter formed were mixed gently for $5 \mathrm{~min}$ and batter were scaled $(150 \mathrm{~g}$ each $)$ into greased baking pans $(7 \mathrm{~cm} \times 6 \mathrm{~cm} \times 3 \mathrm{~cm})$. The batters were proofed for $30 \mathrm{~min}$ at $30^{\circ} \mathrm{C}$ in the oven (Moulinex OPTICHEF Oven - Model BH5) prior to baking. Batter was baked at $160{ }^{\circ} \mathrm{C}$ for $30 \mathrm{~min}$, followed by $180{ }^{\circ} \mathrm{C}$ for $10 \mathrm{~min}$ until a brown crust appeared at the top of breads. Bread loaves were allowed to stay for about $10 \mathrm{~min}$ after baking before de-panning. Bread loaves were arranged in trays and allowed to cool for about $30 \mathrm{~min}$ before further analyses.

Ingredients (Weighed $\mathbf{3 0} \%$ sourdough, baking fat, Flours, salt, sugar, ascorbic acid, water).

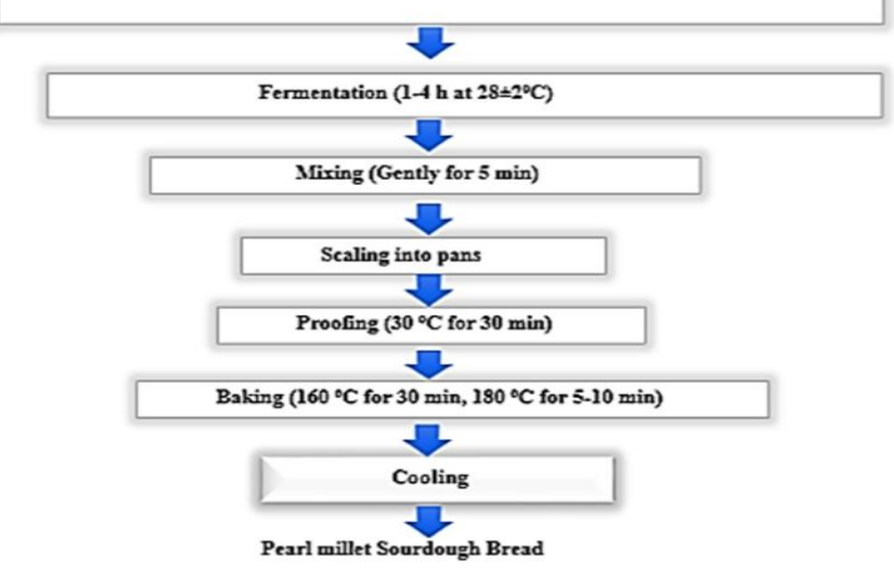

Figure 1 Production of millet sourdough breads

\section{Determination of weight and height in sourdough bread}

Weights of pearl millet sourdough breads were determined using an electronic weighing balance (9YP DY20K, China). Heights of the produced sourdough breads were determined using a graduated meter rule in centimetres $(\mathrm{cm})$. The sourdough bread was measured at three different sides of the loaves. The mean values were taken as the heights of the produced loaves (Edema, 2011).

\section{Determination of loaf volume and specific volume of sourdough bread}

The loaf volumes were determined using modified rapeseed displacement method as described by Rosales-Juarez et al., (2008). The volume of grain was measured in a measuring cylinder and recorded as the initial volume. The bread loaves were placed on a rectangular bread pan of known dimensions. The grains were filled into pan containing bread loaf until full. The displaced volume of grains was taken as final volume. The loaf volume and specific volume of sourdough breads were calculated as described in Equation 1 and 2 respectively.

Loaf volume $\left(\mathrm{cm}^{3}\right)=$ Initial Volume of Grains - Final Volume of grain

Eq. 1

Specific loaf volume $(\mathrm{cm} 3 / \mathrm{g})=$ Loaf volume $/$ Loaf weight

Eq. 2

\section{Determination of proximate composition of sourdough bread}

The percent proximate composition (protein, moisture, crude fat, crude fibre and crude ash contents) of produced sourdough bread was determined according to the method described by AOAC (2005) while the carbohydrate contents were determined by difference of other nutrient from 100 .

\section{Sensory evaluation of sourdough bread}

Produced sourdough breads were subjected to sensory evaluation within $24 \mathrm{~h}$ after baking. Sourdough breads were presented to a 15 man untrained panelists comprising of staff and students of the Federal University of Technology, Akure, Nigeria. Panelists were made to evaluate sourdough bread on the basis of appearance, taste, aroma, texture and overall acceptability using a nine-point hedonic scale ranging from like extremely (9) to dislike extremely (1).

\section{Statistical analysis}

All data were generated in triplicate and analysed using one-way analysis of variance (ANOVA) on Statistical Package for Social Sciences (IBM SPSS Statistics for Windows, Version 18.0 Chicago: SPSS Inc.). The means were separated by Duncan New Multiple Range Tests (DNMRT) at $\mathrm{P} \geq 0.05$.

\section{RESULTS AND DISCUSSION}

Gluten free flours do not lend themselves to satisfactory dough development but can show improved performance when prepared in the form of batter (Sanni $\boldsymbol{e t}$ al., 1998). This account for the use of batter method in the study. The produced sourdough breads was observed to have medium cracks compared to the control samples with little cracks. A crunchy crust was observed in the produced sourdough bread upon cooling. This observation supports the findings of Edema (2011) and Klupsaite et al., (2017) on maize sourdough bread produced from multi-species starter cultures and in Pediococcus pentosaceus fermented lupin bread. Steam gelatinizes starch, denatures protein on bread loaves exterior without forming a hard shell. On removal of steam, retrograded layer of starch dries out forming a thick crunchy crust. The high aroma observed in the sourdough bread might be due to the combined aroma produced as a result of the metabolic activities of starters during fermentation and baking. This supports the earlier report of Klupsaite $\boldsymbol{e t}$ al., (2017) on improved colour, flavour and acidity of fermented sourdough lupin flour. According to Coda et al. (2011) lactic acid bacteria starter cultures aids the improvement of the organoleptic and baking qualities of sourdough bread made from gluten free flours.

Table 1 presents the proximate composition of pearl millet sourdough bread produced using selected lactic acid bacteria and yeast cultures. The protein content of the sourdough breads ranged from $13.07 \%$ to $14.32 \%$. The percent protein content was highest in PMABE (Pearl Millet $+L b$. plantarum $+P$ pentosaseus $+C$. milleri) $(14.32 \%)$ and Pearl Millet + without starter culture (PM + Control) was lowest (13.07\%). The protein contents were higher in the multispecies developed sourdough breads as compared to single-species. However, there were no significant difference between samples PMD (Pearl Millet $+S$. cerevisiae) and PMAE (Pearl Millet $+L b$. plantarum $+C$. milleri) in terms of the percent protein content $(\mathrm{P} \geq 0.05)$. Hence, a protein rich sourdough bread could be developed from Lactobacillus plantarum, Pediococcus pentosaceus, Lactobacillus pentosus and Candida milleri. The presence of starters greatly improves the protein content of produced sourdough bread.

The increased protein content might be due to protein synthesis by the starter cultures in form of enzymes, exopolysaccharides or other metabolites in the sourdoughs. This supports the assertion of Steinkraus (2002) that fermentation improves the nutritive value of foods. Therefore, the findings in this work agrees with the report on maize (Sanni et al., 1998), sorghum and fonio sourdoughs (Edema, 2011), fermented lupin bread (Klupsaite et al., 2017). The starter cultures could function as single cell proteins - an alternative source of protein in 
the developing countries where many dwellers can hardly afford high proteinacious foods because of high costs and poor standard of living.

The percent crude fat content ranged from $8.01 \%$ to $9.32 \%$. The crude fat was highest in PMABCD $(P M+L b$. plantarum $+P$. pentosaceus $+L b$. pentosus + S. cerevisiae $) 9.32 \%$ and lowest in PYE $(P M+C$. milleri) $8.01 \%$. Fat conten influences the shelf life of food products, hence relatively high fat content could be undesirable in dry food products. Saturated fat is capable of promoting rancidity in foods which could lead to the development of unpleasant and odorous compounds (Wasowicz et al., 2004). The crude fat content obtained in this study are within the range of value reported in sour maize bread (Sanni $e$ al., 1998) and in amaranth sourdough bread (Grobelnik, 2009). The percent crude ash content ranged from $1.77 \%$ to $1.99 \%$ and was highest in PMABD (PM + Lb. plantarum + P. pentosaceus + S. cerevisiae) $1.99 \%$. The values obtained in this study are within the range reported in sour maize bread by Sanni $\boldsymbol{e t}$ al. (1998). Thus implying that the sourdoughs could be a rich source of minerals The high mineral content of the sourdoughs might be as a result of improved bioavailability of minerals during the fermentation process.

Dietary fibre is important in reducing the risk of nutrition-related diseases such as diabetes, hypertension, colon cancer, constipation and diverticulosis (Lattimer and Haub, 2010). Percent crude fibre content ranged from $0.77 \%-1.25 \%$ and was highest in PMCDEA $(P M+L b$. pentosus $+S$. cerevisiae $+C$. milleri $+L b$. plantarum $)$ and PMBCDE $(P M+P$. pentosaceus $+L b$. pentosus $+S$. cerevisiae + C. milleri) $1.25 \%$. The percent crude fibre was lowest in control sample $(P M+$ Control) $0.77 \%$. The reduced crude fibre contents in the breads might be due to the degradation of oligosaccharides contained in the pearl millet sourdough by the actions of the microorganisms used as starters. The use of varied cultures could have influenced the variation observed in the crude fibre content of the sourdough bread. However, the crude fibre contents obtained in this study were higher than those reported in sour maize bread (Sanni et al., 1998).

Moisture and water activity of food product determine to a great extent the keeping quality of such foods. The moisture content ranged from $21.08 \%$ to $22.65 \%$ and was highest in PMAC (PM + Lb. plantarum + Lb. pentosus $) 22.65 \%$ and lowest in PMBC (PM+ P. pentosaceus + S. cerevisiae $) 21.08 \%$. The low moisture contents of breads might be due to the high content of oligosaccharides presents in the flour which could increase the water holding capacity of flours.

Table 1 Proximate composition of pearl millet sourdough bread produced using starter cultures

\begin{tabular}{|c|c|c|c|c|c|c|}
\hline Samples & $\begin{array}{l}\text { Protein content } \\
\qquad(\%)\end{array}$ & $\begin{array}{c}\text { Crude fat } \\
(\%)\end{array}$ & $\begin{array}{l}\text { Ash } \\
(\%)\end{array}$ & $\begin{array}{l}\text { Crude fibre } \\
(\%)\end{array}$ & $\begin{array}{l}\text { Moisture } \\
(\%)\end{array}$ & $\begin{array}{c}\text { Carbohydrates } \\
(\%)\end{array}$ \\
\hline$P M+L b$. plantarum (PMA) & $13.46 \pm 0.02^{\mathrm{fg}}$ & $8.13 \pm 0.07^{\mathrm{k}}$ & $1.82 \pm 0.02^{\mathrm{kl}}$ & $1.12 \pm 0.02^{\mathrm{bc}}$ & $21.24 \pm 0.04^{\mathrm{ij}}$ & $54.23 \pm 0.15^{\mathrm{a}}$ \\
\hline$P M+P$. pentosaceus $(\mathrm{PMB})$ & $13.21 \pm 0.02^{\mathrm{i}}$ & $8.08 \pm 0.02^{\mathrm{k}}$ & $1.84 \pm 0.02^{\text {hijk }}$ & $1.23 \pm 0.03^{\mathrm{ab}}$ & $21.63 \pm 0.05^{\mathrm{g}}$ & $54.02 \pm 0.03^{\mathrm{ab}}$ \\
\hline$P M+L b$. pentosus $(\mathrm{PMC})$ & $13.33 \pm 0.01^{\mathrm{h}}$ & $8.32 \pm 0.04^{j}$ & $1.85 \pm 0.01^{\text {ghij }}$ & $0.93 \pm 0.03^{\text {ef }}$ & $22.05 \pm 0.04^{\mathrm{d}}$ & $53.52 \pm 0.03^{\mathrm{c}}$ \\
\hline$P M+$ S. cerevisiae $(\mathrm{PMD})$ & $13.42 \pm 0.01^{\mathrm{fgh}}$ & $8.09 \pm 0.01^{\mathrm{k}}$ & $1.83 \pm 0.02^{\mathrm{ijkl}}$ & $0.93 \pm 0.02^{\mathrm{ef}}$ & $21.72 \pm 0.02^{\mathrm{efg}}$ & $54.03 \pm 0.05^{\mathrm{ab}}$ \\
\hline PM+C. milleri (PME) & $13.45 \pm 0.01^{\mathrm{fg}}$ & $8.01 \pm 0.01^{\mathrm{k}}$ & $1.83 \pm 0.02^{\mathrm{ijkl}}$ & $0.82 \pm 0.02^{\mathrm{fg}}$ & $21.71 \pm 0.02^{\mathrm{efg}}$ & $54.21 \pm 0.02^{\mathrm{a}}$ \\
\hline$P M+$ Lb. plantarum $+P$. pentosaceus $(\mathrm{PMAB})$ & $13.48 \pm 0.01^{\mathrm{f}}$ & $8.52 \pm 0.03^{\mathrm{i}}$ & $1.85 \pm 0.04^{\text {ghi }}$ & $0.84 \pm 0.01^{\mathrm{fg}}$ & $22.53 \pm 0.06^{\mathrm{ab}}$ & $52.76 \pm 0.05^{\mathrm{de}}$ \\
\hline PM+Lb. plantarum $+L b$. Pentosus (PMAC) & $13.38 \pm 0.01^{\text {gh }}$ & $8.98 \pm 0.02^{\text {cde }}$ & $1.89 \pm 0.02^{\mathrm{ef}}$ & $0.86 \pm 0.02^{\mathrm{efg}}$ & $22.65 \pm 0.04^{\mathrm{a}}$ & $52.26 \pm 0.05^{\text {gh }}$ \\
\hline$P M+$ Lb. plantarum + S. cerevisiae (PMAD) & $13.44 \pm 0.03^{\mathrm{fg}}$ & $8.88 \pm 0.01^{\mathrm{fg}}$ & $1.92 \pm 0.01^{\mathrm{cd}}$ & $0.94 \pm 0.01^{\mathrm{ef}}$ & $22.46 \pm 0.03^{\mathrm{b}}$ & $52.37 \pm 0.06^{\text {fgh }}$ \\
\hline$P M+L b$. plantarum $+C$. milleri $(\mathrm{PMAE})$ & $13.39 \pm 0.01^{\mathrm{fgh}}$ & $8.67 \pm 0.02^{\mathrm{hi}}$ & $1.94 \pm 0.01^{\mathrm{bc}}$ & $0.92 \pm 0.01^{\mathrm{ef}}$ & $22.44 \pm 0.01^{\mathrm{b}}$ & $52.62 \pm 0.03^{\mathrm{ef}}$ \\
\hline PM+P. pentosaceus $+L b$. Pentosus (PMBC) & $13.48 \pm 0.03^{\mathrm{f}}$ & $8.75 \pm 0.01^{\text {gh }}$ & $1.99 \pm 0.01^{\mathrm{a}}$ & $1.09 \pm 0.03^{\mathrm{bcd}}$ & $22.04 \pm 0.03^{\mathrm{d}}$ & $52.66 \pm 0.05^{\text {def }}$ \\
\hline$P M+P$. pentosaceus + S. cerevisiae (PMBD) & $14.05 \pm 0.05^{\mathrm{d}}$ & $9.00 \pm 0.10^{\text {bcde }}$ & $1.97 \pm 0.01^{\mathrm{ab}}$ & $1.13 \pm 0.03^{\mathrm{b}}$ & $21.08 \pm 0.01^{\mathrm{k}}$ & $52.75 \pm 0.14^{\mathrm{de}}$ \\
\hline PM+P. pentosaceus + C. milleri (PMBC) & $13.94 \pm 0.04 \mathrm{e}$ & $8.93 \pm 0.04^{\mathrm{ef}}$ & $1.95 \pm 0.01^{\mathrm{bc}}$ & $1.17 \pm 0.03^{\mathrm{ab}}$ & $21.11 \pm 0.02^{\mathrm{jk}}$ & $52.91 \pm 0.12^{\mathrm{d}}$ \\
\hline $\begin{array}{l}\text { PM+Lb. plantarum }+P . \text { pentosaceus }+L b . \text { Pentosus } \\
\text { (PMABC) }\end{array}$ & $13.93 \pm 0.02^{\mathrm{e}}$ & $8.95 \pm 0.02^{\mathrm{def}}$ & $1.98 \pm 0.02^{\mathrm{a}}$ & $1.18 \pm 0.03^{\mathrm{ab}}$ & $21.48 \pm 0.37^{\mathrm{h}}$ & $52.49 \pm 0.42^{\text {efg }}$ \\
\hline $\begin{array}{l}\text { PM+Lb. plantarum }+P . \text { pentosaceus }+ \text { S.cerevisiae } \\
(P \mathrm{MABD})\end{array}$ & $14.17 \pm 0.04^{\mathrm{c}}$ & $9.12 \pm 0.03^{\mathrm{abcd}}$ & $1.99 \pm 0.01^{\mathrm{a}}$ & $1.17 \pm 0.02^{\mathrm{ab}}$ & $21.27 \pm 0.02^{\mathrm{i}}$ & $52.27 \pm 0.12^{\text {gh }}$ \\
\hline $\begin{array}{l}P M+L b . \text { plantarum }+P . \text { pentosaceus }+C . \text { milleri } \\
\text { (PMABE) }\end{array}$ & $14.32 \pm 0.15^{\mathrm{a}}$ & $9.04 \pm 0.04^{\text {bcde }}$ & $1.82 \pm 0.02^{\mathrm{jkl}}$ & $1.10 \pm 0.10^{\mathrm{bcd}}$ & $21.85 \pm 0.04^{\mathrm{e}}$ & $51.86 \pm 0.28^{\mathrm{i}}$ \\
\hline $\begin{array}{l}P M+P . \text { pentosaceus }+L b . \text { pentosus }+ \text { S. cerevisiae } \\
(\mathrm{PMBCD})\end{array}$ & $14.04 \pm 0.05^{\mathrm{d}}$ & $9.06 \pm 0.05^{\text {bcde }}$ & $1.84 \pm 0.01^{\mathrm{ijk} l}$ & $0.98 \pm 0.01^{\mathrm{de}}$ & $21.66 \pm 0.06^{\mathrm{fg}}$ & $52.44 \pm 0.05^{\mathrm{fg}}$ \\
\hline $\begin{array}{l}P M+P . \text { pentosaceus }+ \text { S.cerevisiae }+ \text { C. milleri } \\
(\mathrm{PMBDE})\end{array}$ & $14.07 \pm 0.06^{\mathrm{d}}$ & $9.20 \pm 0.05^{\mathrm{ab}}$ & $1.82 \pm 0.01^{\mathrm{kl}}$ & $0.98 \pm 0.01^{\mathrm{de}}$ & $21.69 \pm 0.01^{\mathrm{efg}}$ & $52.25 \pm 0.09^{\text {gh }}$ \\
\hline$P M+L b$. pentosus + S. cerevisiae + C. milleri (PMCDE) & $14.03 \pm 0.03^{\mathrm{d}}$ & $9.21 \pm 0.03^{\mathrm{ab}}$ & $1.81 \pm 0.01^{1}$ & $0.99 \pm 0.01^{\mathrm{cde}}$ & $21.76 \pm 0.02^{\mathrm{efg}}$ & $52.20 \pm 0.10^{\text {gh }}$ \\
\hline $\begin{array}{l}P M+L b . \text { plantarum }+P . \text { pentosaceus }+ \text { Lb. pentosus }+ \\
\text { S. cerevisiae (PMABCD) }\end{array}$ & $14.21 \pm 0.04^{\mathrm{bc}}$ & $9.32 \pm 0.51^{\mathrm{a}}$ & $1.88 \pm 0.01^{\mathrm{ef}}$ & $0.99 \pm 0.01^{\text {cde }}$ & $21.77 \pm 0.03^{\mathrm{efg}}$ & $52.12 \pm 0.03^{\mathrm{hi}}$ \\
\hline $\begin{array}{l}P M+\text { Lb. plantarum }+ \text { P. pentosaceus }+ \text { S. cerevisiae }+ \\
\text { C. milleri (PMABDE) }\end{array}$ & $14.24 \pm 0.04^{\mathrm{abc}}$ & $9.02 \pm 0.01^{\text {bcde }}$ & $1.91 \pm 0.02^{\mathrm{de}}$ & $1.10 \pm 0.10^{\mathrm{bcd}}$ & $21.82 \pm 0.02^{\mathrm{ef}}$ & $51.92 \pm 0.13^{\mathrm{i}}$ \\
\hline $\begin{array}{l}P M+P . \text { pentosaceus }+ \text { Lb. pentosus }+ \text { S. cerevisiae }+ \\
\text { C. milleri }(\mathrm{PMBCDE})\end{array}$ & $14.26 \pm 0.06^{\mathrm{ab}}$ & $9.10 \pm 0.01^{\mathrm{bcd}}$ & $1.87 \pm 0.02^{\mathrm{fgh}}$ & $1.27 \pm 0.15^{\mathrm{a}}$ & $22.14 \pm 0.13^{\text {cd }}$ & $51.35 \pm 0.23^{\mathrm{j}}$ \\
\hline $\begin{array}{l}P M+L b . \text { pentosus }+ \text { S.cerevisiae }+C . \text { milleri }+L b . \\
\text { plantarum (PMCDEA) }\end{array}$ & $14.27 \pm 0.08^{\mathrm{ab}}$ & $9.18 \pm 0.02^{\mathrm{abc}}$ & $1.87 \pm 0.01^{\mathrm{fg}}$ & $1.27 \pm 0.25^{\mathrm{a}}$ & $22.20 \pm 0.01^{\mathrm{c}}$ & $51.23 \pm 0.34^{\mathrm{j}}$ \\
\hline PM+Control & $13.07 \pm 0.08^{j}$ & $8.07 \pm 0.06^{\mathrm{k}}$ & $1.77 \pm 0.01^{\mathrm{m}}$ & $0.77 \pm 0.02^{\mathrm{g}}$ & $22.53 \pm 0.03^{\mathrm{ab}}$ & $53.81 \pm 0.10^{\mathrm{b}}$ \\
\hline
\end{tabular}

Values are mean of triplicate determinations \pm standard error of mean and different superscripts are significantly different within columns at ( $\mathrm{p} \geq 0.05)$ confidence interval. Legend: $\mathrm{PM}=$ Pearl millet flour; Control = without starter culture, $\mathrm{PM+Control}=$ Pearl Millet + without starter culture.

The values obtained were lower than those reported in wheat bread (35\%), rye bread $(35.5 \%)$ and $28.85 \%$ in maize sourdough bread (Sanni et al., 1998; Edema, 2011). The difference observed between the moisture content could be due to difference in grain morphology (starch content) of cereals used in the studies. The carbohydrate content ranged from $51.28 \%$ to $54.23 \%$. The multiplespecies (PMCDEA, PMBCDE, PMABCD and PMABDE) sourdough samples had the lowest carbohydrate content with a consequent highest amount of protein Unlike the multiple-species inoculated samples, the single-species inoculated samples were characterized with higher values of carbohydrate content. This observation in the multiple-species sourdoughs could be due to an increased metabolic activities of co-existing species. Fermentations with the use of single or multi-species cultures could significantly decrease the soluble, reducing, nonreducing sugars and the starch content of substrates (Diakabana et al., 2014)

Figure 2 presents the loaf weight and volume of pearl millet sourdough bread produced using selected starters. Figure 2 presents the loaf weight and volume of pearl millet sourdough bread produced using selected starters. The weight and loaf volume of sourdough breads ranged from $75.28 \mathrm{~g}-108.32 \mathrm{~g}$ and $89 \mathrm{~cm}^{3}-$ $130 \mathrm{~cm}^{3}$, respectively. PMAE (PM+ Lb. plantarum + C. milleri) had the highestloaf weight $(108.32 \mathrm{~g})$ and volume $\left(130 \mathrm{~cm}^{3}\right)$. Figure 3 presents the loaf height and specific volume of pearl millet sourdough breads produced using selected starters. The heights of the produced sourdough bread ranged from 1.3 $\mathrm{cm}$ to $1.95 \mathrm{~cm}$. The height was highest in PYE $(1.95 \mathrm{~cm})$ and lowest in PM $+L b$. pentosus $(1.3 \mathrm{~cm})$. The use of sourdoughs remarkedly influenced the texture profile of the produced breads as indicated by their specific volumes. The specific volumes of the bread samples were significantly different $(\mathrm{P} \geq 0.05)$ and in the range of $1.0 \mathrm{~cm}^{3} / \mathrm{g}-1.26 \mathrm{~cm}^{3} / \mathrm{g}$. The specific volumes of breads were higher in multi-species starters than those developed using single species starters. The higher specific volumes recorded in multi-species developed pearl millet sourdough breads might be due to the combined metabolic activities of 
homofermentative and heterofermentative microorganisms used as starters thereby resulting in improved leavening of the dough's.

The specific volume was highest in $\mathrm{PMCDE}(P M+L b$. pentosus $+S$. cerevisiae + C. milleri) and PMABCD $\left(1.26 \mathrm{~cm}^{3} / \mathrm{g}\right)$ and lowest in PMBC $\left(1.0 \mathrm{~cm}^{3} / \mathrm{g}\right)$ Specific volumes obtained in this study were higher than those reported by Rosales- Juárez et al. (2008); Sabanis and Tzia (2009) in maize-soybean bread. However, the specific volume in this study are comparable with the report of Plessas et al., (2007) on bread produced using kefir and Lactobacillus casei. Also, Edema (2011) reported similar trend in maize sourdough bread $(0.95$ $\mathrm{cm}^{3} / \mathrm{g}$ ) produced using both single and multi-species starters.

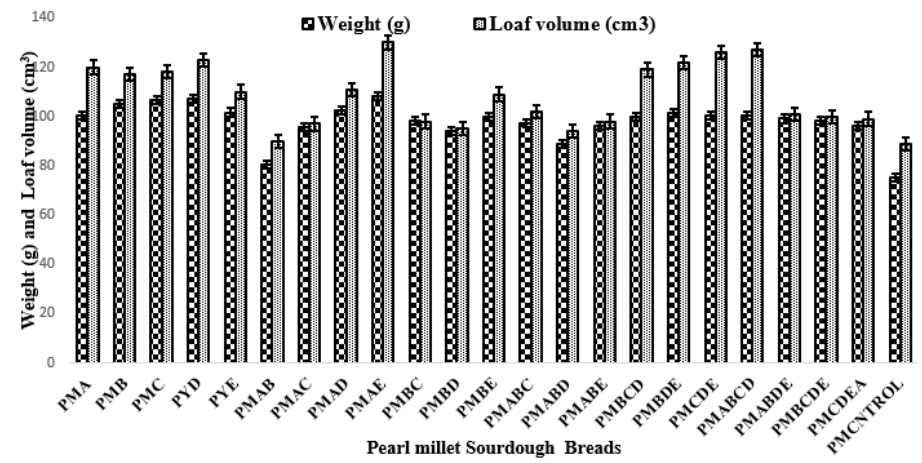

Figure 2 Weight and Loaf volume of pearl millet sourdough bread produced using starters

Legend: $\mathrm{PMA}=$ Pearl Millet flour + Lb. Plantarum, $\mathrm{PMB}=$ Pearl Millet flour $+P$. pentosaceus, $\mathrm{PMC}=$ Pear Millet flour $+L b$. Pentosus, PYD $=$ Pearl Millet flour $+S$. cerevisiae, PYE $=$ Pearl millet flour $+C$. milleri $\mathrm{PMAB}=$ Pearl millet flour $+L b$. plantarum $+P$. pentosaceus, $\mathrm{PMAC}=$ Pearl millet flour $+L b$. plantaru $+L b$. Pentosus, $\mathrm{PMAD}=$ Pearl millet flour $+L b$. plantarum $+S$. cerevisiae, PMAE $=$ Pearl millet flour $+L b$. plantarum $+C$, milleri, $\mathrm{PMBC}=$ Pearl millet flour $+P$, pentosaceus + , Lb. Pentosus, $\mathrm{PMBD}=\mathrm{Pearl}$ mille flour $+P$. pentosace $+S$. cerevisiae, $\mathrm{PMBE}=$ Pearl millet flour $+P$. pentosaceus $+C$. milleri, $\mathrm{PMABC}$ Pearl millet flour $+L b$. plantarum $+P$. pentosaceus $+L b$. Pentosus, PMABD $=$ Pearl millet flour $+L$. Pearl millet flour $+L b$. plantarum $+P$. pentosaceus $+L b$. Pentosus, PMABD $=$ Pearl millet flour $+L b$. plantarum $+P$. pentosaceus $+S$. cerevisiae, $\mathrm{PMABE}=$ Pearl millet flour $+L b$. plantarum $+P$. pentosaceu pentosus $+S$. cerevisiae, $P \mathrm{MBDE}=\mathrm{Pe}$ millet flour $+P$. pentosaceus $+S$. cerevisiae $+C$. milleri, $\mathrm{PMCDE}=$ Pearl millet flour $+L b$. pentosus $+S$. cerevisiae $+C$. milleri, $\mathrm{PMABCD}=$ Pearl millet flour $+L b$. plantarum $+P$. pentosaceus $+L b$. pentosus $+S$ cerevisiae, $\mathrm{PMABDE}=$ Pearl millet flour + Lb. plantarum $+P$. pentosaceus $+S$. cerevisiae $+C$. miller PMBCDE $=$ Pearl millet flour $+P$. pentosaceus $+L b$. pentosus $+S$. cerevisiae $+C$. milleri, PMCDEA Pearl millet flour $+L b$. pentosus $+S$. cerevisiae $+C$. milleri + Lb. Plantarum, $\mathrm{PM}+\mathrm{Control}=$ Pearl mille flour + Control

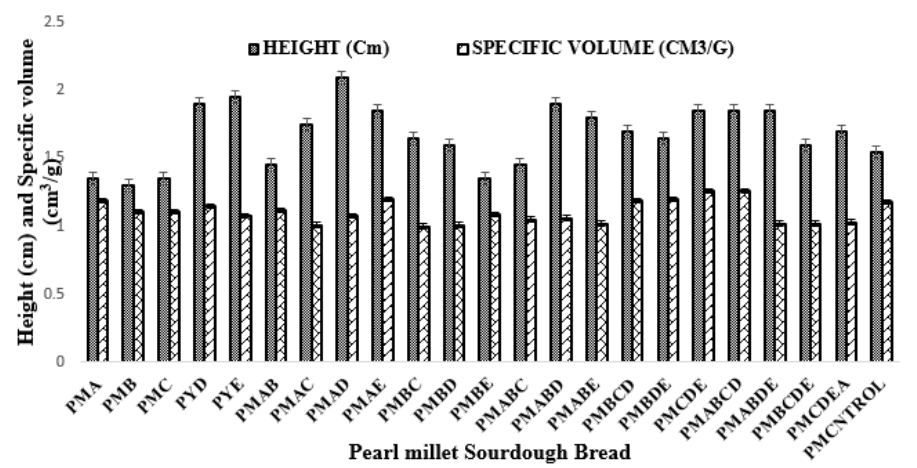

Figure 3 Height and Specific volume of pearl millet sourdough produced using starters

Legend: $\mathrm{PMA}=$ Pearl millet flour $+L b$. Plantarum, $\mathrm{PMB}=$ Pearl millet flour $+P$. pentosaceus, $\mathrm{PMC}=\mathrm{Pea}$ millet flour $+L b$. Pentosus, $\mathrm{PYD}=$ Pearl millet flour $+S$. cerevisiae, $\mathrm{PYE}=$ Pearl millet flour $+C$. miller $\mathrm{PMAB}=$ Pearl millet flour $+L b$. plantarum $+P$. pentosaceus, $\mathrm{PMAC}=$ Pearl millet flour $+L b$. plantarum $+L b$. Pentosus, $\mathrm{PMAD}=$ Pearl millet flour $+L$ b. plantarum $+S$. cerevisiae, $\mathrm{PMAE}=$ Pearl millet flour $+L b$. plantarum $+C$. milleri, $\mathrm{PMBC}=$ Pearl millet flour $+P$. pentosaceus + Lb. Pentosus, $\mathrm{PMBD}=\mathrm{Pearl}$ mille flour $+P$. pentosaceus $+S$. cerevisiae, $\mathrm{PMBE}=$ Pearl millet flour $+P$. pentosaceus $+C$. milleri, $\mathrm{PMABC}=$ Pearl millet flour $+L b$. plantarum $+P$. pentosaceus $+L b$. Pentosus, PMABD $=$ Pearl millet flour $+L b$. plantarum $+P$. pentosaceus $+S$ cerevisiae, $\mathrm{PMABE}=$ Pearl millet flour $+L b$. plantarum $+P$ pentosaceus plantarum + P. pentosaceus + S.cerevisiae, $\mathrm{PMABE}=\mathrm{Pearl}$ millet flour + Lb. plantarum $+P$. pentosaceus + C. milleri, $\mathrm{PMBCD}=$ Pearl millet flour $+P$. pentosaceus $+L b$. pentosus $+S$. cerevisiae, $P \mathrm{MBDE}=\mathrm{Pea}$ millet flour $+P$. pentosaceus + S.cerevisiae $+C$. milleri, $\mathrm{PMCDE}=$ Pearl millet flour + Lb. pentosus $+S$ cerevisiae $+C$. milleri, $\mathrm{PMABCD}=$ Pearl millet flour + Lb. plantarum $+P$. pentosaceus $+L$ L . pentosus $+S$ cerevisiae, PMABDE $=$ Pearl millet flour $+L b$. plantarum $+P$. pentosaceus $+S$. cerevisiae $+C$. miller PMBCDE $=$ Pearl millet flour $+P$. pentosaceus $+L b$. pentosus $+S$. cerevisiae $+C$. milleri, $\mathrm{PMCDEA}$ Pearl millet flour + Lb. pentosus + S.cerevisiae $+C$. milleri + Lb. Plantarum, $\mathrm{PM}+\mathrm{Control}=$ Pearl millet
flour + Control

Table 2 Sensory properties of pearl millet sourdough breads produced using starter cultures

\begin{tabular}{|c|c|c|c|c|c|}
\hline Samples & Appearance & Texture & Taste & Aroma & $\begin{array}{c}\text { Overall } \\
\text { Acceptability }\end{array}$ \\
\hline$P M+L b$. plantarum $(\mathrm{PMA})$ & $7.93 \pm 0.59^{\mathrm{a}}$ & $5.67 \pm 0.90^{\text {bcd }}$ & $4.33 \pm 0.98^{\text {hij }}$ & $6.40 \pm 0.51^{\mathrm{ab}}$ & $5.40 \pm 0.83^{\text {cde }}$ \\
\hline$P M+P$. pentosaceus $(\mathrm{PMB})$ & $7.53 \pm 0.83^{\text {abcd }}$ & $5.87 \pm 1.13^{\mathrm{bc}}$ & $4.40 \pm 0.83^{\text {ghi }}$ & $6.00 \pm 0.85^{\mathrm{bcd}}$ & $6.33 \pm 0.98^{\mathrm{b}}$ \\
\hline PM+Lb. pentosus $(\mathrm{PMC})$ & $7.60 \pm 0.83^{\text {abc }}$ & $6.87 \pm 1.30^{\mathrm{a}}$ & $4.53 \pm 0.74^{\text {efghi }}$ & $6.67 \pm 0.90^{\mathrm{a}}$ & $5.73 \pm 1.22^{\mathrm{c}}$ \\
\hline$P M+$ S. cerevisiae $(\mathrm{PMD})$ & $7.07 \pm 0.70^{\text {bcdef }}$ & $6.20 \pm 1.15^{\mathrm{ab}}$ & $4.73 \pm 0.96^{\text {defgh }}$ & $6.00 \pm 1.00^{\mathrm{bcd}}$ & $5.33 \pm 0.72^{\text {cdef }}$ \\
\hline PM+C. milleri (PME) & $7.33 \pm 0.98^{\text {abcdef }}$ & $5.93 \pm 0.80 \mathrm{bc}$ & $5.07 \pm 0.80^{\text {bcde }}$ & $6.47 \pm 0.74^{\text {ab }}$ & $4.67 \pm 0.72^{\mathrm{fg}}$ \\
\hline$P M+L b$. plantarum $+P$. pentosaceus $(\mathrm{PMAB})$ & $7.13 \pm 0.83^{\text {abcdef }}$ & $4.87 \pm 0.83^{\text {defgh }}$ & $5.80 \pm 0.41^{\mathrm{a}}$ & $5.53 \pm 0.52^{\mathrm{def}}$ & $5.47 \pm 0.74^{\text {cde }}$ \\
\hline
\end{tabular}

Table 2 presents the sensory properties of pearl millet sourdough breads produced from selected starters. The appearance ranged from slightly like (6.60) in PMCDE (Pearl millet + Lb. pentosus $+S$. cerevisiae $+C$. milleri) to moderately like (7.93) in PMA (Pearl Millet $+L b$. plantarum). However, there was no significant difference in appearance of most bread samples $(p \geq 0.05)$. The appearances of pearl millet sourdough breads was comparable to a typhical wheat bread in which the panelist were familiar with, hence its acceptability to consumer. The acceptable appearance of the pearl millet sourdough breads might be due to the obtained creamy colour of pearl millet flour as reported in previous study of Akinola et al. (2017). The colour of substrate flour could influence the acceptability of breads. The texture of the sourdough breads ranged from slightly dislike (4.20) in the control sample (Pearl Millet + Control) to slightly like $(6.87)$ in PMC (Pearl Millet $+L b$. pentosus). However, there was no significant difference between the textures of sourdough breads $(\mathrm{p}>0.05)$. This dislike in the texture of the control sample might be due to a poorly developed protein network resulting from inadequate leavening of the dough since no starter culture was used in the fermentation. The scoring of the sourdough bread with regard to taste ranged from moderately dislike (3.40) in PMBD (Pearl millet flour $+P$ pentosaceus $+S$. cerevisiae) to like (5.80) in PMAB (Pearl millet flour $+L b$. plantarum $+P$. pentosaceus $)$. There was no significant difference in the taste of the samples $(\mathrm{P} \geq 0.05)$. This might be due to the fact that many panelist were not familiar with this type of bread (tart bread) hence their low scoring. The aroma ranged from slightly dislike (4.27) in the control sample (Pearl Millet + Control) to slightly like (6.73) in PMABD (Pearl Millet + Lb. plantarum $+P$ pentosaceus $+S$. cerevisiae $)$ and $\mathrm{PMBCDE}(\mathrm{PM}+P$. pentosaceus + Lb. pentosus + $S$. cerevisiae $+C$. milleri). The overall acceptability's of the pearl millet sourdough breads were adjudged acceptable mostly in the developed multiplespecies sourdough breads compared to the single-species and control. The overall acceptability ranged from slightly dislike (4.40) in PMBE (Pearl Millet $+P$. pentosaceus $+C$. milleri) to slightly like (7.20) in PMABE (Pearl Millet $+L b$ plantarum $+P$. pentosaceus $+C$. milleri). A similar trend was reported by Sanni et al. (1998) in maize sourdough breads and fermented lupin bread (Klupsaite $\boldsymbol{e}$ al., 2017) as judgment of panelists have been traced to traditional food habits (Sanni et al., 1998). Consumers of bread in ecological zones like Nigeria traditionally believe and accept white and sweetened bread in whatever form it is prepared. Since sourdough bread is a specialty bread it should be encouraged on the merit of its potential as a functional food 


\begin{tabular}{|c|c|c|c|c|c|}
\hline$P M+L b$. plantarum $+L b$. Pentosus (PMAC) & $7.13 \pm 0.83^{\text {abcdef }}$ & $5.13 \pm 0.92^{\text {cdefg }}$ & $5.60 \pm 0.63^{\mathrm{ab}}$ & $6.33 \pm 0.62^{\mathrm{ab}}$ & $5.20 \pm 0.77^{\text {cdef }}$ \\
\hline$P M+$ Lb. plantarum $+S$. cerevisiae $(\mathrm{PMAD})$ & $7.27 \pm 0.80^{\text {abcdef }}$ & $5.20 \pm 0.77^{\text {cdef }}$ & $5.40 \pm 0.51^{\mathrm{abc}}$ & $6.13 \pm 0.35^{\text {abcd }}$ & $5.47 \pm 0.83^{\text {cde }}$ \\
\hline$P M+L b$. plantarum $+C$. milleri $(\mathrm{PMAE})$ & $7.67 \pm 0.98^{\mathrm{abc}}$ & $5.13 \pm 1.81^{\text {cdefg }}$ & $4.87 \pm 0.74^{\text {defgh }}$ & $6.60 \pm 0.51^{\mathrm{ab}}$ & $5.53 \pm 0.64^{\text {cde }}$ \\
\hline PM+P. pentosaceus $+L b$. Pentosus (PMBC) & $6.73 \pm 0.88^{\text {def }}$ & $5.07 \pm 1.16^{\text {cdefg }}$ & $3.67 \pm 0.82^{\mathrm{jkl}}$ & $6.60 \pm 0.63^{\mathrm{ab}}$ & $5.00 \pm 0.65^{\text {defg }}$ \\
\hline$P M+P$. pentosaceus + S. cerevisiae (PMBD) & $7.27 \pm 0.80^{\text {abcdef }}$ & $4.73 \pm 0.80^{\text {efghi }}$ & $3.40 \pm 0.74^{1}$ & $6.47 \pm 0.83^{\mathrm{ab}}$ & $5.13 \pm 0.92^{\text {cdef }}$ \\
\hline$P M+P$. pentosaceus + C. milleri (PMBC) & $7.47 \pm 0.83^{\text {abcde }}$ & $5.20 \pm 1.01^{\text {cdef }}$ & $5.00 \pm 0.53^{\text {cdef }}$ & $5.67 \pm 0.72^{\text {cde }}$ & $4.40 \pm 0.74^{\mathrm{g}}$ \\
\hline $\begin{array}{l}\text { PM+ Lb. plantarum }+P . \text { pentosaceus }+L b . \\
\text { Pentosus(PMABC) }\end{array}$ & $6.67 \pm 1.05^{\mathrm{ef}}$ & $5.27 \pm 0.96^{\text {cde }}$ & $4.40 \pm 0.51^{\text {ghi }}$ & $6.33 \pm 0.72^{\mathrm{ab}}$ & $4.47 \pm 0.52^{\mathrm{g}}$ \\
\hline $\begin{array}{l}P M+\text { Lb. plantarum }+ \text { P. pentosaceus }+ \text { S.cerevisiae } \\
(P \mathrm{MABD})\end{array}$ & $6.73 \pm 1.28^{\text {def }}$ & $5.07 \pm 0.96^{\text {cdefg }}$ & $5.13 \pm 0.35^{\mathrm{bcd}}$ & $6.73 \pm 0.59^{\mathrm{a}}$ & $5.13 \pm 0.64^{\text {cdef }}$ \\
\hline$P M+$ Lb. plantarum $+P$. pentosaceus $+C$. milleri $(\mathrm{PMABE})$ & $7.60 \pm 1.12^{\mathrm{abc}}$ & $4.40 \pm 0.91^{\text {efghi }}$ & $4.33 \pm 0.72^{\mathrm{hij}}$ & $6.40 \pm 1.06^{\mathrm{ab}}$ & $7.20 \pm 0.94^{\mathrm{a}}$ \\
\hline$P M+P$. pentosaceus + Lb. pentosus + S. cerevisiae $(\mathrm{PMBCD})$ & $7.60 \pm 0.99^{\mathrm{abc}}$ & $4.47 \pm 0.74^{\text {efghi }}$ & $4.93 \pm 0.80^{\text {cdef }}$ & $5.53 \pm 0.99^{\mathrm{def}}$ & $4.93 \pm 0.59^{\mathrm{defg}}$ \\
\hline$P M+$ P. pentosaceus + S.cerevisiae + C. milleri $(\mathrm{PMBDE})$ & $7.27 \pm 0.80^{\text {abcde }}$ & $4.33 \pm 0.62^{\text {fghi }}$ & $5.13 \pm 0.64^{\text {bcd }}$ & $6.13 \pm 0.64^{\text {abcd }}$ & $5.33 \pm 0.62^{\text {cdef }}$ \\
\hline PM+Lb. pentosus + S. cerevisiae $+C$. milleri (PMCDE) & $6.60 \pm 1.06^{\mathrm{ef}}$ & $5.20 \pm 0.77^{\text {cdef }}$ & $4.47 \pm 0.52^{\text {ghi }}$ & $6.13 \pm 0.64^{\mathrm{abcd}}$ & $5.53 \pm 0.64^{\text {cde }}$ \\
\hline $\begin{array}{l}\text { PM+Lb. plantarum }+P . \text { pentosaceus }+ \text { Lb. pentosus }+S . \\
\text { cerevisiae }(\mathrm{PMABCD})\end{array}$ & $7.87 \pm 0.92^{\mathrm{ab}}$ & $5.13 \pm 0.99^{\text {cdefg }}$ & $4.07 \pm 0.70^{\mathrm{ijk}}$ & $5.33 \pm 0.72^{\mathrm{ef}}$ & $5.27 \pm 0.80^{\text {cdef }}$ \\
\hline $\begin{array}{l}P M+L b . \text { plantarum }+P . \text { pentosaceus }+S . \text { cerevisiae }+C \text {. } \\
\text { milleri (PMABDE) }\end{array}$ & $7.07 \pm 0.96^{\text {bcdef }}$ & $4.87 \pm 1.06^{\text {defgh }}$ & $3.80 \pm 0.77^{\mathrm{ijk}}$ & $5.53 \pm 0.92^{\mathrm{def}}$ & $5.20 \pm 0.94^{\text {cdef }}$ \\
\hline $\begin{array}{l}\text { PM+P. pentosaceus }+ \text { Lb. pentosus }+ \text { S. cerevisiae }+C . \\
\text { milleri }(\mathrm{PMBCDE})\end{array}$ & $6.87 \pm 1.13^{\text {cdef }}$ & $5.20 \pm 1.01^{\text {cdef }}$ & $4.53 \pm 0.52^{\text {efghi }}$ & $6.73 \pm 0.59^{\mathrm{a}}$ & $5.47 \pm 1.13^{\text {cde }}$ \\
\hline $\begin{array}{l}P M+L b . \text { pentosus }+ \text { S.cerevisiae }+C . \text { milleri }+ \text { Lb. plantarum } \\
(\mathrm{PMCDEA})\end{array}$ & $6.73 \pm 0.80^{\text {def }}$ & $4.27 \pm 1.10^{\mathrm{hi}}$ & $4.40 \pm 0.63^{\text {ghi }}$ & $5.20 \pm 0.86^{\mathrm{ef}}$ & $5.67 \pm 0.72^{\mathrm{cd}}$ \\
\hline PM+Control & $7.00 \pm 0.93^{\text {def }}$ & $4.20 \pm 0.86^{\mathrm{i}}$ & $5.13 \pm 0.52^{\mathrm{bcd}}$ & $4.27 \pm 0.96^{\mathrm{f}}$ & $5.47 \pm 0.64^{\text {cde }}$ \\
\hline
\end{tabular}

Values are mean of triplicate determinations \pm standard error of mean and different superscripts are significantly different within columns at $(\mathrm{p} \geq 0.05)$ confidence interval. Legends : Like extremely - 9; Moderately like - 8; Slightly like -7; Like - 6; Neither like nor dislike - 5; Slightly dislike - 4; Moderately dislike -3; Extremely dislike - 2; Dislike $-1, \mathrm{PM}=$ Pearl millet flour; Control $=$ without starter culture

\section{CONCLUSION}

Sourdough bread is gradually gaining attention in Africa owing to its nutritiona benefits. The use of multi-species starters influenced the proximate composition of pearl millet sourdough breads. Percent crude protein content increases with increasing number of starters in pearl millet sourdoughs breads. The use of multispecie cultures influences the loaf volume and specific loaf volume of pearl millet sourdough bread. A combined metabolic activity of homofermentative and heterofermentative starters could results in improved baking quality of sourdough breads. An acceptable specialty breads production from pearl millet flour requires the use of multi-species starters comprising of both homofermenters and heterofermenters. A strategic combination of Lactobacillus plantarum, Lactobacillus pentosus and Saccharomyces cerevisiae could give a desirable fermentation with improved nutrient quality if carried out under controlled conditions. Saccharomyces cerevisiae have been implicated in dough development, however, this study have shown that Candida milleri could also be a substitute in dough development in the pastry industry. Further studies on the nutritional and health benefits of millet sourdough breads is needful. Adequate enlightening on the potential health benefits of sourdough bread could enhance its acceptance in the tropics where white bread is a staple.

\section{REFERENCES}

Akinola, S.A., Badejo, A.A., Osundahunsi, O.F., \& Edema, M.O., (2017). Effect of Pre-Processing Techniques on Pearl Millet Flour and Changes in Technological Properties". International Journal of Food Science and Technology. 52(4), 992-999. http://dx.doi.org/10.1111/ijfs.13363

Akinola, S.A., \& Osundahunsi, O.F., (2017). Lactic Acid Bacteria and Yeast Diversities in Spontaneously Fermented Millet Sourdoughs. Journal of Microbiology Biotechnology and Food Science, 6(2):1030 - 1035 http://doi:10.15414/jmbfs.2017.6.4.1030-1035

AOAC, 2005. Official method of analysis. Association of Official Analytical Chemist International, Maryland, USA.

Arendt, E. K., Ryan, L. A. M., \& Dal Bello, F., (2007). Impact of sourdough on the texture of bread. Food Microbiology, 24(2):165-174. https://doi.org/10.1016/j.fm.2006.07.011

Balasubramanian, S., \& Viswanathan, R., (2010). Influence of moisture content on physical properties of minor millets. Journal of Food Science and Technology 4, 279-284. http://doi:10.1007/s13197-010-0043-z

Chavan R. S., \& Chavan, S. R., (2011). Sourdough Technology-A Traditional Way for Wholesome Foods: A Review. Comprehensive Reviews in Food Science and Food Safety 10:170-183. http://doi:10.1111/j.1541-4337.2011.00148.x

Coda, R., Di Cagno, R. C., Rizzello, G., Nionelli, L., Edema, M.O., \& Gobbetti, M. (2011). Utilization of African grains for Sourdough Bread Making. Journal of Food Science, 76: M329-M335. http://doi:10.1111/j.1750-3841.2011.02240.x De Vuyst, L., \& Vancanneyt, M., (2007). Biodiversity and Identification of Sourdough Lactic Acid Bacteria. Food Microbiology, 24:120-127. https://doi.org/10.1016/j.fm.2006.07.005
Diakabana, P., Niama, R.F., Mvilla, A.C., Louzolo, I., Kobawila, S.C., \& Louembe, D. (2014). Behaviour of Fermentable Sugars in the Traditional Production Process of Cassava Bioethanol. Advanced Journal of Food Science and Technology, 6(10):1104-1111.

Edema M.O., (2011). A Modified Sourdough Procedure for Non-Wheat Bread from Maize Meal. Food Bioprocess Technology 4:1264-1272. http://dx.doi.org/10.1007/s11947-009-0252-5

Edema, M. O., (2013). Use of Non-wheat Flours in Nigerian Bread Production. TWOWS Africa Intern. Journal of Science and Technology, 4 (1 \& 2) 51-58.

Edema, M. O., \& Sanni, A. I., (2008). Functional properties of selected starter cultures for sour maize bread. Food Microbiology 25: 616 625.http://dx.doi.org/10.1016/j.fm.2007.12.006

Grobelnik-Mlakar, S., (2009). Nutrition Value and Use of Grain Amaranth: Potential Future Application in Bread Making. Agricultura 7: 5-15.

Hounhouigan, D. J., Nout, M. J. R., Nago, C. M., Houben, J. H., \& Rombouts, F. M., (1999). Use of Starter Cultures of Lactobacilli and Yeast in the Fermentation of 'mawe', an African Maize Product. Tropical Science. 39: 220-226.

Kaisa P., Laura, F., \& Kati, K., (2009). Sourdough and Cereal Fermentation in a Nutritional Perspective. Food Microbiology. 26: 693-699. https://doi.org/10.1016/j.fm.2009.07.011

Klupsaite, D., Juodeikiene, G., Zadeike, D., Bartkiene, E., Maknickiene, Z., \& Liutkute, G. (2017). The influence of lactic acid fermentation on functional properties of narrow-leaved lupine protein as functional additive for higher value wheat bread. LWT-Food Science and Technology, 75, 180-186. https://doi.org/10.1016/j.1wt.2016.08.058

Kołożyn-Krajewska, D., \& Dolatowski, Z. J., (2012). Probiotic meat products and human nutrition. Process Biochemistry, 47(12), 1761-1772. http://doi.org/10.1016/j.procbio.2012.09.017

Lattimer J.M., \& Haub, M.D., (2010). Effects of Dietary Fibre and its Components on Metabolic Health. Nutrients. 2(12):1266-1289. http://doi:10.3390/nu2121266

Moore, M., Dal Bello, F., \& Arendt, E., (2008). Sourdough Fermented by Lactobacillus plantarum Improves the Quality and Shelf life of Gluten-free Bread. European Food Research Technology. 226: 1309-1316. http://doi:10.1007/s00217-007-0659-z

Ogunbanwo T.S., \& Ogunsanya T. B. (2012). Quality assessment of 'oti-oka'like beverage produced from pearl millet. Journal of Applied Biosciences, 51, 3608 3617.

Ottogalli G, Galli A, \& Foschino R. (1996). Italian bakery products obtained with sourdough: characterization of the typical microflora. Advance Food Science 18:131-44. http://hdl.handle.net/2434/180142

Padalino, L., Conte, A., \& Del Nobile, M. A. (2016). Overview on the General Approaches to Improve Gluten-Free Pasta and Bread. Foods, 5(4), 87 http://doi:10.3390/foods5040087

Plessas, S., Trantallidi, M., Bekatorou, A., Kanellaki, M., Nigam, P., \& Koutinas, A. A. (2007). Immobilization of kefir and Lactobacillus casei on brewery spent grains for use in sourdough wheat bread making. Food Chemistry, 105(1), 187 194. https://doi.org/10.1016/j.foodchem.2007.03.065 
Rosales-Juárez, M., González-Mendoza, B., López-Guel, E. C., Lozano-Bautista, F., Chanona-Pérez, J., \& Gutiérrez-López, G., (2008). Changes in Dough Rheological Characteristics and Bread Quality as a Result of the Addition of Germinated and Non-Germinated Soybean Flour. Food Bioprocess Technology, 1:152-160. http://doi:10.1007/s11947-007-0004-3

Sabanis, D., \& Tzia, C., (2009). Effect of Rice, Corn and Soy Flour Addition on Characteristics of Bread Produced from Different Wheat Cultivars. Food and Bioprocess Technology. 2: 68-79. http://doi:10.1007/s11947-007-0037-7

Sanni, A.I., Onilude, A.A., \& Fatungase, M.O. (1998). Production of Sour Maize Bread Using Starter-cultures. World Journal of Microbiology \& Biotechnology.14: 101-106. http://doi:10.1023/A:1008836803338

Schober, T., Schober, J., Bean, S., \& Boyle, D. (2007). Gluten-free Sorghum Bread Improved by Sourdough Fermentation: Biochemical, Rheological, and Microstructural Background. Journal of Agriculture and Food Chemistry. 55: 5137-5146. http://doi:10.1021/jf0704155

Schwab, C., Mastrangelo, M., Corsetti, A., \& Ga“ Nzle, M. (2008). Formation of Oligosaccharides and Polysaccharides by Lactobacillus reuteri LTH5448 and Weissella cibaria 10M in Sorghum Sourdoughs. Cereal Chemistry. 85: 679-684. http://hdl.handle.net/11575/7404

Statistical Package For Social Sciences, International. (2011). IBM SPSS statistics for Windows, version 20.0. New York: IBM Corp.

Steinkraus K.H., (2002). Fermentations in World Food Processing. Comprehensive Review in Food Science and Food Safety.1:23-32. http://doi:10.1111/j.1541-4337.2002.tb00004.x

Thiele, C., G“Anzle, M.G., \& Vogel R. F., (2002). Contribution of sourdough lactobacilli, yeast, and cereal enzymes to the generation of amino acids in dough relevant for bread flavor. Cereal Chemistry 79:45-51. https://doi.org/10.1094/CCHEM.2002.79.1.45

Wasowicz, E., Gramza, A., Hes, M., Jelen, H., Korczak, J., Malecka, M. Mildner-Szkudlarz, S., Rudzinska, M., Samotyja, U. \& Zawirska-Wojtasiak, R., (2004). Oxidation of lipids in food. Polish Journal of Food and Nutrition Sciences, 13:87-100. https://doi.org/10.31883/pjfns 